\title{
Analisis Metode Pattern Based Approach Question Answering System Pada Dataset Hukum Islam Berbasis Bahasa Indonesia
}

\author{
Ade Iriani Sapitri, Said Al-Faraby, Adiwijaya \\ Fakultas Informatika, Universitas Telkom Bandung, Indonesia \\ Email: 1adeiriani@student.telkomuniversity.ac.id, 2saidalfaraby@telkomuniversity.ac.id, \\ 3adiwijaya@telkomuniversity.ac.id
}

\begin{abstract}
Abstrak
Hukum islam merupakan ketentuan perintah dari Allah SWT yang memiliki hukum yang berbeda-beda. Dibutuhkan waktu yang lama dalam proses pencarian informasi secara manual mengingat banyaknya jenis dari hukum islam. Dari permasalahan di atas dengan bantuan Question Answering System dapat mengatasi permasalahan tersebut. Tujuan dari penelitian ini untuk membantu pengguna dalam mencari informasi yang dibutuhkan dengan masukan berupa pertanyaan dengan kategori properti yaitu (OBJECT) Apa, (PERSON) Siapa, (LOCATION) Dimana, (TIME) Kapan dan (COUNT) Berapa. Pada penelitian ini Question Answering System diimplementasikan dengan metode Pattern Based Approach berdasarkan penggolongan pola. Pada penelitian ini didapatkan hasil akurasi jawaban sebesar $64,5 \%$ dan pada setiap tipe kategori pertanyaan “Apa","Kapan","Berapa","Siapa" dan "Dimana" dengan akurasi jawaban sebesar 63,3\%, 65\%, 73,3\%, 65\%, dan 40\%. Dari hasil akurasi yang didapatkan bahwa metode Pattern Based Approach mampu diimplementasikan pada Question Answering System untuk mengatasi permasalahan yang terjadi diatas.
\end{abstract}

Kata kunci: hukum islam, question answering system, pattern based approach

\section{Abstract}

Islamic law is a provision of the command of Allah SWT which has different laws. It takes a long time in the process of searching information manually given the many types of islamic law. From the above problems with the help of Question Answering System can solve the problem. The purpose of this study is to assist usesrs in finding the required information with input in the form of question with property category (OBJECT) What, (PERSON) Who, (LOCATION) Where, (TIME) When and (COUNT) How much. Research Question Answering System is implemented with the Pattern Based Approach method based on pattern classification. In this research we get the result of accuracy of answer equal $64,5 \%$ in every type of question category "What","When","How much", "Who", and "Where" with answer accuracy equal to 63,3\%, 65\%, 73,3\%, 65\% and $40 \%$. From the accuracy results obtained that the method of Pattern Based Approach is able to be implemented in Question Answering System to solve the above problems

Keywords: islamic law, question answering system, pattern based approach

\section{PENDAHULUAN}

Perkembangan teknologi saat ini sudah sangat berkembang pesat salah satunya adalah peningkatan pesat dalam penyampaian informasi. Sehingga dalam menemukan suatu informasi sangat dibutuhkan pemahaman dan waktu yang relatif cukup lama untuk melakukan proses pencarian dikarenakan harus membaca dan melakukan proses penyariangan terlebih dahulu untuk mencari informasi yang diinginkan. Salah satu cara mengatasi permasalahan tersebut adalah dengan bantuan sistem pencarian informasi search engine namun dengan bantuan tersebut user masih harus melakukan eksplorasi data yang ingin dicari pada dokumen yang diinginkan. Hal ini tentunya sangat tidak efektif, baik dari segi waktu maupun dari segi keakuratan jawaban. Melihat dari permasalahan tentang hukum islam, hukum islam merupakan ketentuan perintah dari Allah SWT, setiap perintah yang dianjurkan Allah SWT memiliki hukum yang berbeda-beda. Dibutuhkan waktu yang lama dalam proses pencarian secara manual mengingat banyaknya jenis dari hukum islam.

Dilihat dari permasalahn tersebut Question Answering System dapat membantu proses tersebut dengan mengijinkan user untuk menginputkan pertanyaan dan memperoleh jawaban dengan cepat dan ringkas. Question Answering System bukanlah sistem baru karena telah banyak penelitian yang telah diteliti dan dipublikasikan ${ }^{[8]}$. Namun, saat ini masih sedikitnya pengimplementasian Question Answering System berbasis Bahasa Indonesia. Sehingga dengan pengimplementasian Question Answering System dengan metode Pattern Based Approach mampu membantu permasalahan yang dibutuhkan pada dataset hukum islam berbasis Bahasa Indonesia.

\section{TEORITIS}

\subsection{Information Retrieval System}

Information Retrieval merupakan sistem yang digunakan untuk menemukan informasi yang relevan dalam menemukan material berupa dokumen yang bersifat tidak terstruktur untuk memenuhi kebutuhan informasi dalam skala besar ${ }^{[5]}$. Dalam Information Retrieval atau sistem temu kembali memiliki banyak obyek yang menjadi kajian sistem temu kembali, diantaranya Question answering IR system, Cross-language retrieval, Speech retrieval, Music retrieval, dan Image retrival ${ }^{[2]}$.

\subsection{Question Answering System}


Question answering system merupakan sebuah sistem yang memiliki tujuan untuk menampilkan jawaban dari pertanyaan yang diberikan oleh user. Question Answering System merupakan kombinasi dari berbagai disiplin ilmu diantaranya Information Retrieval dengan Natural Language Processing ${ }^{[3]}$. Ada beberapa faktor yang perlu diperhatikan, yaitu : sumber informasi yang akan digunakan untuk menjawab pertanyaan (database, corpus, web), user, tipe pertanyaan, format dan cara menghasilkan jawaban, kebutuhan akan sumber linguistik, evalua- si, dan penyajian output. Faktor tersebut baik secara langsung maupun tidak akan menentukan kompleksitas dan performansi dari QA system ${ }^{[9]}$.

Pada penelitian yang dilakukan oleh Lukman Fakih tentang QAS terjemahan Al-Quran menggunakan Named Entity Recognition didapatkan hasil akurasi jawaban sebesar 73\% dengan tipe pertanyaan siapa kapan dan dimana. Sedangkan, pada penelitian yang dilakukan oleh Agus Umriadi tentang QAS pada dokumen bahasa Indonesia dengan pertanyaan bersifat list didapatkan hasil akurasi jawaban sebesar 26\% Siapa, 36,3\% Dimana, 70\% Kapan dan $40 \%$ Berapa.

\subsection{Arsitektur Question Answering System}

Dalam pembangunan Question Answering System banyak arsitektur yang dapat digunakan. OpenEphyra merupakan framework dalam pembangunan Question Answering System dengan menggunakan metode Pattern Based Approach. Secara umum komponen inti terdiri dari yaitu : analisa pertanyaan question analysis, pembentukan query (query generation), pencarian (search), pembentukan kandidat jawaban dan penilaian jawaban [6].

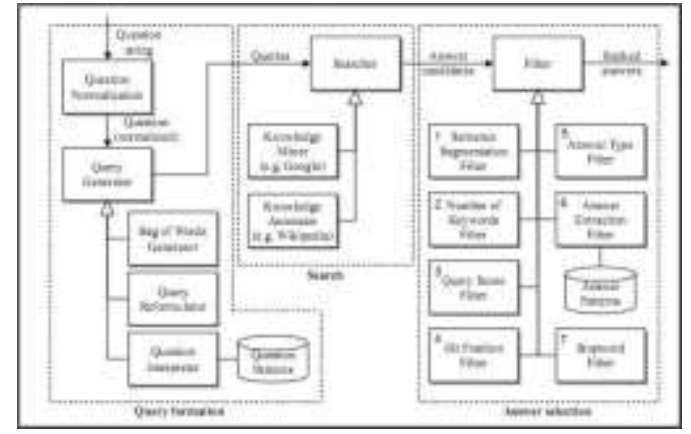

Gambar 1 Arsitektur Question Answering System dengan pendekatan pattern learning[6]

\subsection{Pattern Based Approach}

Pattern Based Approach merupakan metode Question Answering System yang ditentukan berdasarkan penggolongan pola. Dari hasil pengujian sebelumnya Pattern Based Approach pada Question Answering System berbahasa indonesia didapatkan hasil akurasi interpretasi sebesar $90 \%$ dan akurasi jawaban sebesar 35\% ${ }^{[6]}$. Diketahui dalam penelitian tersebut didapatlah kekurangannya terhadap adaptasi OpenEphyra ke bahasa Indonesia diperlukannya modifikasi atau mengubah komponen spesifik bahasa alami seperti : NE tagger, stemmer, phrase chunker, (POS) tagger dan tokenizer.

\section{ANALISA DAN PEMBAHASAN}

Tujuan dari penelitian ini adalah membuat sistem yang mampu melakukan proses pencarian jawaban dari pertanyaan yang telah diinputkan oleh user. Sistem ini hanya dapat menjawab pertanyaan dengan named entity LOCATION, PERSON, COUNT, TIME dan OBJECT dari dataset yang telah dibuat pada buku ensiklopedia hukum islam dan artikel internet. Sehingga, kalimat pertanyaan yang dapat diinputkan oleh user juga terbatas pada kalimat pertanyaan seperti "Apa", "Siapa", "Dimana", "Kapan" dan "Berapa". Pada penelitian ini mengimplementasikan tiga tahapan proses yang membangun arsitektur umum Question Answering System, seperti yang ditunjukkan pada gambar 1 [4]. Adapun fungsi yang dijalankan pada setiap tahapan proses implementasi Question Answering System dijelaskan sebagai berikut.

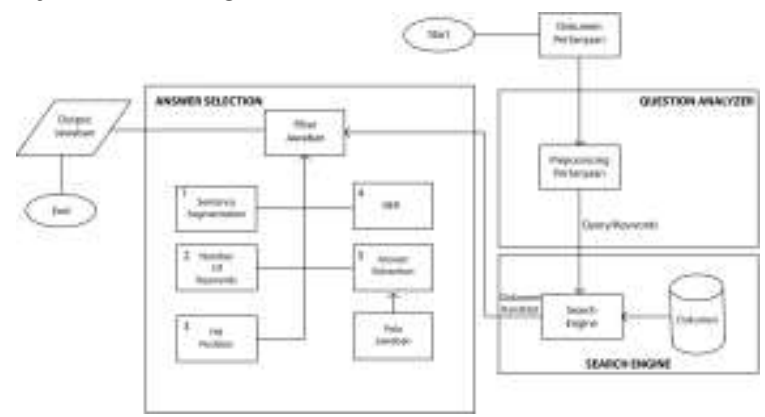

Gambar 2. Gambaran Umum Sistem 


\subsection{Question Analyzer}

Tahap question analyzer akan menerima masukan berupa pertanyaan dari user. Kemudian, pertanyaan akan dilakukan normalisasi pertanyaan. Contoh pertanyaan "Apa hukum salat duha ?" maka sistem akan mengubah menjadi "apa hukum salat duha". Selanjutnya dicari kata yang menjadi kata tanya dan didapatkan kata "apa" sebagai kata tanya. Kata tanya "apa" akan disimpan untuk pencocokan pada hasil Named Entity Recognation yang dilakukan pada proses answer selection. Sehingga hasil analisis dari interpretasi pertanyaan didapatkan :
1. Kata tanya
: Apa
2. Kandidat keywords
: hukum, salat, duha

\subsection{Query Generator}

Pada proses query generator pada penelitian ini menggunakan metode bag of words. Metode bag of words menggunakan hasil analisis dari pertanyaan yang sudah dinormalisasi dari question analyzer untuk dijadikan keywords dalam pencarian dokumen. Pada tahap question analyzer sistem menyimpan kata tanya "apa" sehingga hasil dari bag of words berupa keywords.

Keywords : ['hukum', 'salat', 'duha']

\subsection{Search Engine}

Pada proses search engine dilakukan dengan menggunakan proses model ruang vektor. Adapun tahapan dari model ruang vektor sebagai berikut.

1. Pengindeksan(indexing) dokumen.

Pada tahap pengindeksan dilakukan proses normalisasi pada seluruh dokumen dataset. Tahap awal yaitu parsing (pemecahan) kata pada dokumen. Tahap kedua yaitu stopwords dan tahap terakhir adalah stemming. Untuk hasil pengindeksan dokumen dataset dapat dilihat pada lampiran.

2. Pembobotan kata term weighting.

Pada tahap ini adalah menjelaskan hasil perhitungan pembobotan kata sebelumnya. Dalam pembobotan kata term weighting terdapat dua hal yang penting yaitu Term Frequency(tf) dan Inverse Document Frequency (idf).

a. Term Frequency (tf) merupakan frekuensi kemunculan term (t) pada dokumen (d) dapat dilihat pada persamaan 1 berikut.

$$
t f(d, t)=f(d, t)
$$

Hasil pembobotan kata Term Frequency pada seluruh dokumen dataset dapat dilihat pada lampiran.

b. Inverse Document Frequency (idf) merupakan pengurangan diminasi term yang sering muncul diberbagai dokumen. Faktor (idf) dari term $(\mathrm{t})$ dalam sebuah dokumen dapat dilihat dari persamaan 2 berikut.

$$
i d f(t)=\log \left(\frac{n}{d f(t)}\right)
$$

Hasil pembobotan kata Inverse Document Frequency (idf) pada seluruh dokumen dataset dapat dilihat pada lampiran.

c. Term frequency-inverse document frequency merupakan perkalian antara (tf) dan (idf) yang dapat menghasilkan performansi yang lebih baik. Kombinasi bobot dari term $(\mathrm{t})$ pada dokumen $(\mathrm{d})$ dapat dilihat dari persamaan 3 berikut.

$$
t f-i d f(d, t)=t f(d, t) x i d f(t)
$$

Hasil pembobotan kata Termfrequency-Inverse document frequency (tf-idf) pada seluruh dokumen dataset dapat dilihat pada lampiran.

3. Ukuran kemiripan Similariy Measure

Salah satu ukuran kemiripan teks yang populer adalah cosine similarity, ukuran ini menghitung nilai cosinus sudut antara dua vektor. persamaan cosine similarity dapat dilihat pada persamaan 4 berikut.

$$
\operatorname{similarity}(d, q)=\frac{d . q}{\|d\| \cdot\|q\|}
$$

Pada kasus ini query yang digunakan adalah ['hukum','salat','duha'] sehingga, untuk hasil ukuran kemiripan pada query tersebut dapat dilihat pada lampiran.

\subsection{Answer Selection}


Pada tahap ini answer selection menerima dokumen kandidat jawaban yang diperoleh pada proses search engine. Kemudian akan dilakukan proses selanjutnya untuk menghasilkan jawaban. Dalam tahapan ini terdapat alur kerja sebagai berikut ${ }^{[7]}$.

\section{Sentence Segmentation}

Tahap awal seleksi jawaban adalah segmentasi kalimat. Diketahui dari proses search engine sebelumnya bahwa, pada dokumen 02 yang menjadi dokumen kandidat jawaban. Sehingga dilakukan proses segmentasi seperti berikut :

\section{Tabel 1. Hasil Sentence Segmentation}

\begin{tabular}{cl}
\hline Kalimat ke- & Hasil Segmentasi Kalimat \\
\hline Kalimat 1 & salat duha adalah salat yang dilakukan orang muslim diwaktu duha. \\
Kalimat 2 & hukum salat duha adalah sunnah. \\
Kalimat 3 & $\begin{array}{l}\text { waktu salat duha adalah ketika matahari mulai naik kurang lebih tujuh hasta } \\
\text { sejak terbitnya hingga waktu zuhur. }\end{array}$ \\
Kalimat 4 & jumlah rakaat salat duha minimal dua rakaat dan maksimal duabelas rakaat. \\
Kalimat 5 & dan dilakukan dalam satuan dua rakaat sekali salam.
\end{tabular}

2. Number Of Keywords

Setelah dilakukan segmentasi kalimat pada dokumen kandidat, tahap selanjutnya adalah menentukan apakah kalimat tersebut memenuhi syarat sebagai kandidat jawaban yang ditentukan dari jumlah kata kunci dengan menggunakan persamaan 5 .

$$
M \geq \sqrt{[K-1]}+1
$$

Dengan :

$\mathrm{K}=$ jumlah kata kunci atau keywords pada pertanyaan

$\mathrm{M}=$ jumlah kata kunci atau keywords yang juga terdapat pada kalimat yang menjadi kandidat jawaban.

Kalimat akan dibuang jika jumlah keywords yang terdapat pada kalimat tidak memenuhi kondisi diatas. Jika memenuhi kondisi maka dilakukan perhitungan skor dengan rumus persamaan 6 berikut.

$$
\text { Skor }=\frac{M}{K} \times 10
$$

Sehingga didapatlah hasil perhitungan dengan keywords ['hukum','salat','duha'] yang memenuhi persamaan tersebut. $M \geq[3-1]+1=2,41$

a. Kalimat $1: 4 \geq 2,41$ Kandidat kalimat

b. Kalimat $2: 3 \geq 2,41$ Kandidat kalimat

c. Kalimat $3: 2 \geq 2,41$

d. Kalimat $4: 2 \geq 2,41$

e. Kalimat $5: 0 \geq 2,41$

Dilihat dari perhitungan diatas bahwa kalimat 1 dan kalimat 2 menjadi kandidat kalimat jawaban.

3. Hit Position

Pada proses number of keyword didapat skor pada masing-masing kandidat jawaban. Pada proses hit position jawaban dilakukan pengurutan berdasarkan skor yang sudah diperoleh. Contoh pengurutan skor berdasarkan data hasil number of keyword.

a. Kalimat $1:$ [13.00] salat duha adalah salat yang dilakukan orang muslim diwaktu duha

b. Kalimat $2:$ [10.00] hukum salat duha adalah sunnah

4. Named Entity Recognation

Named Entity Recognation dilakukan untuk mendapatkan proses ekstraksi informasi berupa jenis named entity pada teks [1]. Ada lima jenis tipe named entity pada penelitian ini yaitu OBJECT, TIME, COUNT, PERSON dan LOCATION. Kemudian kandidat kalimat pada tahap sebelumnya dilakukan proses NER untuk menghasilkan tipe named entity. Sehingga didapatkan hasil NER dari kandidat kalimat sebagai berikut ${ }^{1}$.

a. NER : ["Diwaktu Duha","TIME"]

b. NER : ['Hukum Salat",'OBJECT"]

Selanjutnya, proses hasil named entity dilakukan pencocokan dengan kata tanya yang telah disimpan sebelumnya. Diketahui kata tanya yang disimpan sebelumnya adalah "Apa" kata tanya apa merupakan tipe named entity dari OBJECT. Sehingga kandidat kalimat yang mengandung named entity OBJECT diambil untuk dilakukan proses ektraksi jawaban pada tahap answer extraction.

5. Answer Extraction 
Tahap answer extraction akan menghasilkan ekstraksi jawaban dari kandidat kalimat kemudian akan diubah menjadi pola jawaban yang telah dibuat sebelumnya. Untuk pola jawaban yang telah dibuat dapat dilihat pada lampiran. Diketahui pola jawaban untuk pertanyaan "Apa hukum salat duha" adalah

$$
\text { Pola Jawaban } \quad:(\text { OBJECT })<T\rangle\langle C\rangle\langle C\rangle \text { adalah }\langle P\rangle
$$

Pada pola jawaban tag $<P>$ merupakan potongan kalimat yang akan diekstrak menjadi jawaban. Sehingga dari kalimat 2 didapatkan jawaban dari hasil ekstrak $\langle P\rangle$ sebagai berikut.

Jawaban : hukum salat duha adalah sunnah

\section{IMPLEMENTASI}

Performansi dari sebuah Qusetion Answering System diukur dengan melakukan evaluasi terhadap jawaban yang dikembalikan sebagai output dari input pertanyaan. Question Answering System merupakan evaluasi berskala besar terhadap sistem yang mengembalikan jawaban bukan daftar dokumen sebagai respon atas sebuah pertanyaan ${ }^{[10]}$. Adapun spesifikasi dari perancangan Question Answering System adalah sebagai berikut :

1. Pada penelitian ini disediakan 110 pertanyaan dan memiliki jawaban.

2. Sebagai sumber informasi, digunakan kumpulan dokumen dari buku ensiklopedia hukum islam dan artikel internet.

\subsection{Hasil Pengujian}

Proses terakhir dalam penelitian ini adalah evaluasi, metode yang diusulkan akan dievaluasi tingkat keakuratannya. Data hasil evaluasi dapat dilihat pada lampiran daftar tabel 8. Berikut hasil dari beberapa testing yang dilakukan dapat dilihat pada tabel 2 dan 3.

Tabel 2. Hasil Pengujian Menggunakan NER

\begin{tabular}{ccccc}
\hline & True & False & $\begin{array}{c}\text { Total } \\
\text { Pertanyaan }\end{array}$ & Persentase \\
\hline Apa & 19 & 11 & 30 & $63.3 \%$ \\
Kapan & 13 & 7 & 20 & $65 \%$ \\
Berapa & 22 & 9 & 30 & $73.3 \%$ \\
Siapa & 13 & 7 & 20 & $65 \%$ \\
Dimana & 4 & 6 & 10 & $40 \%$ \\
Total & $\mathbf{7 1}$ & $\mathbf{3 9}$ & $\mathbf{1 1 0}$ & $\mathbf{6 4 . 5 \%}$ \\
\hline
\end{tabular}

Tabel 3. Hasil Pengujian tanpa NER

\begin{tabular}{ccccc}
\hline & True & False & $\begin{array}{c}\text { Total } \\
\text { Pertanyaan }\end{array}$ & Persentase \\
\hline Apa & 7 & 23 & 30 & $23.3 \%$ \\
Kapan & 2 & 18 & 20 & $10 \%$ \\
Berapa & 16 & 14 & 30 & $53.5 \%$ \\
Siapa & 6 & 14 & 20 & $30 \%$ \\
Dimana & 3 & 7 & 10 & $30 \%$ \\
Total & $\mathbf{3 4}$ & $\mathbf{7 6}$ & $\mathbf{1 1 0}$ & $\mathbf{3 0 . 9 \%}$ \\
\hline
\end{tabular}

Dari hasil pengujian tersebut kemudian dihitung nilai akurasi dengan menggunakan rumus 7.

$$
\text { Akurasi }=\frac{\text { Jawaban Benar }}{\text { Total Pertanyaan }} \times 100 \%
$$

Berikut hasil akurasi dengan penggunaan Named Entity Recognation dan tanpa menggunakan Named Entity Recognation dari penelitian ini.

$$
\begin{aligned}
& \text { Akurasi }=\frac{71}{110} \times 100 \%=64,5 \% \\
& \text { Akurasi }=\frac{34}{110} \times 100 \%=30,9 \%
\end{aligned}
$$




\subsection{Analisis Hasil Pengujian}

Dari hasil pengujian yang dilakukan dengan 110 sampel pertanyaan didapatkan 71 jawaban benar dan 39 jawaban salah dengan menggunakan named entity. Dari hasil analisis tersebut didapatkan beberapa faktor yang menyebabkan jawaban dari pertanyaan yang dinputkan salah.

1. Sistem tidak mengeluarkan jawaban dikarenakan pada proses number of keywords tidak menghasilkan kandidat kalimat sehingga tidak dapat dilakukan proses ektrak jawaban. Hal ini dapat diatasi dengan inputan pertanyaan yang lebih spesifik. Selain itu, sistem tidak mengeluarkan jawaban dikarenakan named entity yang tidak spesifik sehingga tidak dapat mengekstrak jawaban dari kandidat kalimat yang didapatkan. Hal ini dapat diatasi dengan pengembangan model named entity

2. Kandidat jawaban dapat diekstrak oleh sistem namun mengeluarkan hasil jawaban yang banyak. Ini disebabkan karena kandidat kalimat memiliki pola yang sama dengan pola jawaban yang telah dibuat. Untuk meminimalisir permasalahan ini dapat dilakukan dengan pengembangan pola jawaban.

Dari hasil pengujian tanpa menggunakan Named Entity didapatkan hasil yang rendah dikarenakan kalimat kandidat jawaban memiliki pola yang sama dengan pola jawaban, sehingga akan mengeluarkan semua jawaban sesuai dengan pola yang telah dibuat sebelumnya. Selain itu, jika sistem mengeluarkan jawaban kosong maka pada proses number of keywords yang tidak menghasilkan kandidat kalimat dan named entity yang belum spesifik.

\section{KESIMPULAN}

Setelah dilakukannya analisis Question Answering System dengan metode Pattern Based Approach pada dataset hukum islam yang bersumber dari buku ensiklopedia hukum islam dan internet maka dapat disimpulkan sebagai berikut :

1. Secara umum, metode Pattern Based Approach dapat diterapkan untuk rancangan Question Answering System pada dataset hukum islam dengan kategori pertanyaan yaitu orang, waktu, tempat, objek dan jumlah.

2. Hasil penelitian ini berupa jawaban dari pertanyaan yang diajukan

3. Semakin spesifik/unik pertanyaan yang diajukan maka semakin baik jawaban yang diberikan oleh sistem.

4. Performansi dari sistem dapat ditingkatkan dengan pengembangan pola. Dimana semakin banyak pola yang dikembangkan maka semakin besar kemungkinan sistem akan menemukan kembali informasi.

5. Diharapkan pada penelitian selanjutnya mampu menganalisa lebih dalam tentang Natural Language Processing (NLP) khususnya NER, diperlukan pengembangan model NER lebih spesifik agar hasil ekstrak jawaban akan mendapatkan hasil yang baik.

\section{REFERENCES}

[1] S. Amarappa and S. Sathyanarayana. Kannada named entity recognition and classification (nerc) based on multinomial nal" ive bayes (mnb) classifier. arXiv preprint arXiv:1509.04385, 2015.

[2] R. Baeza-Yates, B. Ribeiro-Neto, et al. Modern information retrieval, volume 463. ACM press New York, 1999.

[3] T. Dong, U. Furbach, I. Glöckner, and B. Pelzer. A natural language question answering system as a partici- pant in human q\&a portals. In IJCAI Proceedings-International Joint Conference on Artificial Intelligence, volume 22, page 2430, 2011.

[4] M. A. Greenwood and H. Saggion. A pattern based approach to answering factoid, list and definition qu- estions. In Coupling approaches, coupling media and coupling languages for information retrieval, pages 232-243. LE CENTRE DE HAUTES ETUDES INTERNATIONALES D'INFORMATIQUE DOCUMEN- TAIRE, 2004.

[5] C. D. Manning, C. D. Manning, and H. Schütze. Foundations of statistical natural language processing. MIT press, 1999.

[6] N. Schlaefer, P. Gieselmann, and G. Sautter. The ephyra qa system at trec 2006.

[7] N. Schlaefer, J. Ko, J. Betteridge, M. A. Pathak, E. Nyberg, and G. Sautter. Semantic extensions of the ephyra qa system for trec 2007. In TREC, volume 1, page 2, 2007.

[8] T. Strzalkowski and S. Harabagiu. Advances in open domain question answering, volume 32. Springer Science \& Business Media, 2006.

[9] H. Toba and M. Adriani. Pattern based approach in indonesian question-answering system. University of Indonesia, Bandung, 2010.

[10] E. M. Voorhees. The trec question answering track. Natural Language Engineering, 7(4):361-378, 2001. 